However, when both levers were present, nearly all responses occurred on the light-correlated lever during compounding. This indicates that light and its lever were salient and preferred stimuli, even though there was no suggestion of this dominance from the pattern of responding when only one lever was exposed. This result cannot be explained in terms of a higher frequency of responding being maintained by the light during single $\mathrm{S}^{\mathrm{D}}$ presentations. This occurred with three of the five Ss but nearly equal frequencies occurred with the other two Ss. And, both Meltzer and Masaki (1973) and Miller (1973) reported a number of instances in which the tone maintained the higher frequency, but most responding still occurred on the light-correlated lever at compounding.

Combining two lights of different intensity did not significantly affect responding when either one or both levers was present. This also occurred with lights of each intensity with one lever present, but when the lights were of equal intensity and both levers were present, responding significantly increased. It is not clear why responding did not also increase when the lights of different intensity were combined and both levers were present. Five of the eight Ss emitted most of their responses on the lever correlated with the lower intensity light, indicating that the higher intensity light did not overshadow or obscure the lower intensity light. Also, Miller (1971) reported summation when he used lights of similar low and high intensity but which were correlated with the same single lever.

When both levers were exposed, no significant preference for a particular lever was found during compounding, regardless of light intensity. This outcome was quite different from what occurred when light and tone were the $S D_{S}$. The lever correlated with the higher frequency of responding during single $S^{D}$ presentations was the lever on which most responses were emitted during compounding in only 9 of 16 instances.

These results suggest that the effects of combing $S D_{S}$ is sensitive to whether the following variables were same or different: the response manipulanda, the modalities of the $S^{D_{S}}$, and the values of the $S^{D_{S}}$. The effects obtained with one combination of variables were not necessarily predictive of what was obtained when a different combination was used.

\section{REFERENCES}

Meltzer, D., \& Masaki, M. A. Measures of stimulus control and stimulus dominance. Bulletin of the Psychonomic Society, 1973, 1, 28-30.

Miller, L. Compounding of discriminative stimuli from the same and different sensory modalities. Journal of the Experimental Analysis of Behavior, 1971, 16, 337-342.

Miller, L. Compounding of discriminative stimuli that maintain responding on separate response levers. Journal of the Experimental A nalysis of Behavior, 1973, 20, 57-69.

Weiss, S. J. Summation of response strengths instrumentally conditioned to stimuli in different sensory modalities. Journal of Experimental Psychology, 1964, 68, 151-155.

Weiss, S. J. Stimulus compounding in free-operant and classical conditioning: A review and analysis. Psychological Bulletin, 1972, 78, 189-208.

(R eceived for publication June 24, 1974.)

\title{
Dependence and thought as determinants of interpersonal hostility*
}

\author{
ABRAHAM TESSER and ROBERT JOHNSON \\ Institute for Behavioral Research and Department of Psychology \\ University of Georgia, Athens, Georgia 30602
}

\begin{abstract}
It was assumed that thought tends to make attitudes more extreme (by making relevant cognitions more consistent) and that dependence on another tends to focus one's thoughts on that other. This lead to the predictions that attitudes toward an initially disliked other would become more negative as a function of opportunity for thought, dependence on other, and opportunity by dependence. Dissonance theory leads to an opposite prediction: Attitudes will become less negative as a function of opportunity, dependence, and opportunity by dependence. Although results were not completely consistent with either prediction, they were better accounted for by the first.
\end{abstract}

A recent series of studies has been concerned with attitude change as a function of simply thinking about the attitude object. The conceptualization guiding these studies is based on two assumptions: (1) thinking about some attitude object has an impact on the cognitions concerning that object so that they tend toward greater consistency with the initial attitude direction, and (2) there is a causal relationship between the cognitions and affect associated with some attitude object. These assumptions lead to the hypotheses that merely thinking

*The authors are indebted to Chris Leone for his assistance in running Ss. This paper is sponsored by Robert M. Pollack, who takes full editorial responsibility for its contents. about some object will produce more polarized attitudes and, since thought is a time dependent process, the longer one thinks about the attitude object the more polarized will his attitude become. Both of these hypotheses have received some support (Sadler \& Tesser, 1973; Tesser \& Conlee, in press).

The thought polarization hypothesis sometimes makes predictions that differ from those oi other theories. For example, it predicts that the more we think about someone we initially dislike the more we will come to dislike that person. Assuming dependence on that other heightens one's predisposition to concentrate his thoughts on that other; then, given the opportunity for 
thought, the greater the dependence on an initially dislikeable person the more we will come to dislike that person. Dissonance theory makes a different prediction. The cognitions that $\mathrm{P}$ is dependent on $\mathrm{O}$ and that $\mathrm{O}$ is malevolent are dissonant. One way of reducing this dissonance would be to increase the attractiveness of $O$. Furthermore, the greater the opportunity for thought the more pronounced this relationship should be.

\section{METHOD}

Ss were 48 males enrolled in introductory psychology. Upon reporting in pairs for an experiment dealing with "student opinions," Ss were led to separate rooms to fill out an attitude questionnaire. Each then used a speaker system to describe himself and listen to his "partner" describe himself since "... most conversations concerning attitude issues are between ... acquaintances." In reality the "partner's" self-description was a tape recording (see Sadler \& Tesser, 1973) designed to make the S dislike him. ${ }^{1}$ Ss were then told that they were to write the most convincing arguments they could in favor of three of their attitudes. The $10 \mathrm{Ss}$ with the best argument would win $\$ 5$ each. Dependence on their partners was manipulated by telling half the Ss that their partners' reactions to their argument would be relatively important (high dependence) or unimportant (low dependence) in determining who won. While the $E$ was "... preparing materials for the attitude task ..." half of the Ss in each dependency condition were advised to think about their partner (high opportunity for thought); the other half in each condition were distracted from thinking about their partner by working on a "general information test" (low opportunity for thought). After $90 \mathrm{sec}$, Ss were asked to give their impressions of their partner.

Dependent measures included summed attraction ratings over two 7-point items concerning how much the S liked and would want to work with his partner, ratings on six evaluative semantic differential scales, and a S-generated list of thoughts concerning his partner (for each thought the $S$ indicated whether it was positive, negative, or neutral/irrelevant). Following this, Ss filled out a postexperimental questionnaire, were probed for suspicion, and completely debriefed.

\section{RESULTS}

Each of the manipulations appear to have been successful. Ss indicated, on the postexperimental questionnaire, that their partner dominated their thoughts more and that they thought about more aspects of their partner in the high- compared to the low-opportunity condition $(p<.01)$. Further, Ss listed more thoughts about their partner in the high-opportunity condition ( $p<.05$, one-tailed). Ss also indicated that their partner's opinion of their arguments was a more important determinant of whether they would win in the high-compared to the low-dependence condition $(p<.01)$, thus validating that manipulation. Finally, Ss' attitude toward their partner appeared to be negative. They generated more negative than positive cognitions about him and the summed attraction measure was lower than the theoretical neutral point, as were the means on each of the six semantic differential scales.

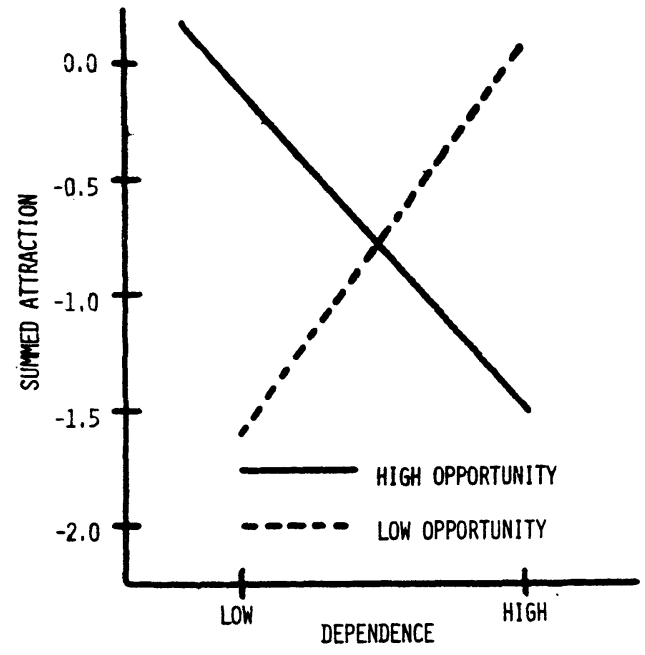

Fig. 1. Attraction to other as a joint function of dependence and opportunity for thought in the dislikable other condition. Scale ranges -6.0 (maximum disliking) to +6.0 (maximum liking).

The postexperimental questionnaire results provide consistent support for the experimental hypotheses. Ss indicated that, as a result of thought, their feelings about their partner became more negative $(p<.01)$. Since filling out a questionnaire and listing cognitions requires thought, Ss were also asked to scale the impact of these activities on their feelings. On both items, their feelings reportedly changed in a negative direction $(p<.01)$. Dependence was expected to make thought more focused and, therefore, produce more negative attitudes. As predicted, Ss indicated that the importance of their partner's opinion (for winning the prize, i.e., their dependence on partner) caused them to increase their disliking for him $(\mathrm{p}<.01)$.

Although number of positive and number of negative thoughts were unaffected by the experimental manipulations, number of neutral thoughts was affected by opportunity and dependence. High dependence on a dislikable partner produced more neutral cognitions than low dependence $(p<.05)$; high opportunity for thought produced more neutral cognitions than low opportunity for thought $(p<.01)$.

Dependence and opportunity for thought interacted $(p<.01)$ in influencing summed attraction. As can be seen in Fig. 1, when Ss are given an opportunity to think about the dislikable other, the greater the dependence on him the less they like him $(p<.05)$. While low opportunity for thought was expected to dampen the effects of dependence, the effects of dependence were reversed with low opportunity for thought $(p<.05)$. From another perspective, when Ss were highly dependent on the other, the greater their opportunity for thought the more negative their attitude $(p<.05)$. Given low dependence, the relation was unexpectedly 
reversed $(p<.05)$ instead of reduced. Total semantic differential scores were not significantly affected by the experimental manipulations. However, dependence and opportunity for thought interacted in a way similar to that shown in the figure for two of the scales considered individually: considerate/inconsiderate $(\mathrm{p}<.01)$ and fair/unfair $(\mathrm{p}<.05)$.

\section{DISCUSSION}

Ss' retrospective reports on the postexperimental questionnaire provide consistent support for the hypotheses in that both thought and dependence led to increased negativity. The results with the thought listing measures were not as straightforward. Only neutral thoughts were significantly affected by the manipulations. Perhaps saying negative things about another is socially undesirable and Ss derogate their partners through "faint praise." Since saying nice things about others is the socially desirable and normative thing to do, relatively neutral statements may be construed as negative. If this line of reasoning is correct, we would expect neutral cognitions to behave in accordance with the predictions for negative cognitions. This, in fact, was generally the case. The number of neutral cognitions was positively related to dependence and opportunity. Furthermore, although the interaction did not approach significance, opportunity to think had a greater impact in the high-dependence condition than in the low-dependence condition.

Opportunity and dependence interacted in determining summed attraction (and two of the semantic differential scales). Since the interaction does not reflect differences in degree of relationship but rather direction of relationship, dissonance theory and thought polarization theory are inadequate as complete explanations of the results. However, thought polarization theory is more consistent with the data than dissonance theory. First, the Ss' lack of choice with respect to Person B makes any application of dissonance theory questionable. Further, given high rather than low opportunity for thought, dissonance theory predicts a maximally positive relationship and thought polarization theory a maximally negative relationship between dependence and attitudes: The relationship was significantly negative. Given high rather than low dependence, dissonance theory predicts a maximally positive relationship and thought polarization theory predicts a maximally negative relationship between opportunity and attitudes: The relationship was significantly negative. Since the positive relationships occur under conditions expected to produce the smallest negative relationships from the perspective of thought polarization theory and since the negative relationships occur under conditions expected to produce the largest positive relations from the perspective of dissonance theory, thought polarization theory seems to give a more adequate accounting.

Thought polarization theory, however, cannot easily accommodate the positive relationships obtained. Perhaps the crucial determinant of direction of relationship is opportunity for thought. When Ss are not given an opportunity to think about the other and they are not dependent on him, it is easy to dismiss him as someone who is rather dislikable. Without having given the matter much thought, it is equally easy to judge him as relatively neutral. And under high dependence this is the most self-serving judgment. On the other hand, when one does think about someone upon whom he is not dependent, given the experimental setting and the social desirability of making positive evaluations of others, perhaps reasons and excuses for the other's negative behavior are reviewed or generated so as to make the $S$ appear generous in his evaluation. If one is dependent on the other, he cannot afford to be generous so thought tends to polarize attitudes.

\section{REFERENCES}

Sadler, O. \& Tesser, A. Some effects of salience and time upon interpersonal hostility and attraction during social isolation. Sociometry, 1973, 36, 99-112.

Tesser; A. \& Conlee, M. C. Some effects of time and thought on attitude polarization. Journal of Personalty \& Social Psychology, in press.

\section{NOTES}

1. A likable partner condition was also run. Since the thought manipulation appeared ineffective and each of the theories made the same predictions in this condition, no further reference will be made to it here. A more complete description of all the procedures and results is available from the authors.

(Received for publication June 12, 1974.) 